nHPT is perhaps responsible for the onset and progression of the similar osseous complications as described in classical PHPT. Further longitudinal studies are required to help devise best management plan to mitigate against the skeletal encumbrance of nHPT.

Disclosure of Interests: None declared

DOI: 10.1136/annrheumdis-2021-eular.1095

\section{AB0611 OSTEOPOROSIS IN RHEUMATOID ARTHRITIS: A NECESSARY EVIL?}

S. Athimni ${ }^{1}$, S. Bouden ${ }^{1}$, A. Ben Tekaya ${ }^{1}$, A. Dghais ${ }^{1}$, O. Saidane ${ }^{1}$, R. Tekaya ${ }^{1}$, I. Mahmoud', L. Abdelmoula ${ }^{1} .^{1}$ Charles Nicolle Hospital, Rheumatology, Tunis, Tunisia

Background: Rheumatoid arthritis (RA) is a chronic inflammatory disease that is characterized by local and general bone loss. Osteoporosis (OP) is one of the most frequent comorbidities associated with RA. Many factors are incriminated in bone loss in RA such as inflammation, glucocorticoid (GC) use, and immobility. Objectives: -To determine the prevalence of OP in a population of actual RA patients.

-To determine the risk factors of bone mineral density (BMD) reduction

Methods: One hundred-fifty-two RA followed in the rheumatology department between 2015-2020 were enrolled in the study. The diagnosis of RA was established according to the American College of rheumatology/European League Against Rheumatism (ACR/EULAR) criteria 2010. BMD in lumbar spine and total hip was systematically measured in the recruited patients. Measures were taken with dual-energy x-ray absorptiometry (DEXA), and age-specific values were compared with pooled values from a local population of healthy subjects free from earlier fractures.

Results: The mean age was $42.7 \pm 13$ years. The sex ratio $M / F$ was 0.24 . The mean onset disease was $6 \pm 1.8$ years. Fifty-sex patients $(36.3 \%)$ were receiving conventional treatment DMARDs and $96(63.6 \%)$ were under biological treatment. $35.5 \%$ were taken steroids with mean doses at $7.7 \pm 3.3 \mathrm{mg} / \mathrm{day}$. RF and ACPA were positive respectively in $87.3 \%$ and $82.4 \%$ of the patients. The mean disease activity score DAS28CRP was $4.8 \pm 2.7$.

Sixty-eight point eight $68.8 \%$ of the RA population had bone loss: $37.5 \%$ had osteopenia and $31.3 \%$ had OP. Regarding the OP group, sex ratio M/F was 0.45 . The mean age was $42 \pm 5.3$ years. Among the 31 women, $77.4 \%$ had postmenopausal OP. The BMI average was $31.18 \pm 6.19 \mathrm{~kg} / \mathrm{m}^{2}$. Fifteen patients $(33.33 \%)$ had OP in the hip site and 20 patients had OP in the lumbar site $(48.8 \%)$. Ten patients had both trabecular and cortical OP.

Advanced age, glucocorticoid use and high DAS28CRP were independent risk factors for OP (respectively $p=0.04, p=0.02$ and $p=0.01$ ). Body mass index, smoking, disease duration high Health Assessment Questionnaire (HAQ) score $(p=0.545)$ and smoking $(p=0.326)$ were not associated with high risk of OP. The biological treatment was not a protective factor in OP $(p=0.972)$. All the population subjects were free from earlier fractures, the fractural risk estimated by dint of the mean FRAX ${ }^{\mathrm{TM}}$ score was at $1.4 \pm 2.3$.

Conclusion: Previous studies estimated that, approximately, osteoporosis affected one-third of RA patients which is in concordance with our study. Advanced age, glucorticoid treatment and severe disease were the most common risk factor in our study.

Disclosure of Interests: None declared

DOI: 10.1136/annrheumdis-2021-eular.1235

\section{AB0612 THE FRACTURE PREVENTION UNIT OF THE VIRGEN MACARENA HOSPITAL REDUCES THE GAP IN THE MANAGEMENT OF OP, PARTICULARLY IN MALES AND MEETS IOF/ESCEO QUALITY STANDARDS}

B. Hernández-Cruz ${ }^{1}$, F. J. Olmo Montes ${ }^{2}$, M. J. Miranda García ${ }^{2}$, M. D. Jimenez Moreno $^{2}$, M. A. Vázquez Gómez ${ }^{3}$, M. Giner García ${ }^{3}$, M. A. Colmenero Camacho ${ }^{2}$, J. J. Pérez Venegas ${ }^{1}$, M. J. Montoya García ${ }^{3} .{ }^{1}$ Hospital Universitario Virgen Macarena, Rheumtology, Sevilla, Spain; ${ }^{2}$ Hospital Universitario Virgen Macarena, Internal Medicine, Sevilla, Spain; ${ }^{3}$ University Medical School, Internal Medicine, Sevilla, Spain

Background: The Virgen Macarena University Hospital belongs to the Public Health System of Andalusia and serves 481,296 inhabitants in Seville, Spain. In 2018 the Fracture Liaison Service switched to a multidisciplinary unit.

Objectives: To describe FLS, to know the characteristics of patients with emphasis on gender differences and to know the completion of International Osteoporosis Foundation quality standards.

Methods: Prospective, observational, analytical, research of usual clinical practice. All the consecutive patients attended from May 2018 to October 2019, $\geq 50$ years, with a fragility fracture (occurred in the previous 24 months) were included. The study was approved by the Ethics Committee, Code 1084-N-16.
Results: Our FLS is a type A multidisciplinary Unit, with a high level of intervention in the evaluation, estimation of fracture risk and fall risk, treatment prescription and follow-up of the patients. We included 408 patients, $80 \%$ females, one third with $\geq 80$ years. Fragility fractures recorded in 328 women were hip $(132,40 \%)$, clinical vertebral $(81,25 \%)$ and no hip no vertebral ( 115 $35 \%)$. Those recorded in 82 males were hip (53, 66\%), clinical vertebral $(20$ $24 \%)$ and no hip no vertebral $(9,10 \%), p=0.0001$. Males had a higher rate of secondary causes of OP, drinker, and smoking. The most relevant gender difference was the low percentage of patients receiving pre-FF OP treatment. Forty-nine (16\%) women versus $9(7 \%)$ males had received it at some point in their life, $p=0.04$. Two hundred and seventy-one (86\%) women vs 48 males $(63 \%)$ had received it at after their FF in their reference unit, and all them were treated after the FLS evaluation. The probability of a male not receiving prior treatment was $2.5(95 \% \mathrm{Cl} 1.01-6.51) ; \mathrm{p}=0,04$. This probability was 0.64 (0.38-1.09) after the FF. After twelve months of follow-up in FLs, 96\% continued treatment, with no differences between men and women. The completion of IOF quality standards was bad (red light) for patient identification items and FLS reference time. It was poor (amber traffic light) for initial OP screening standard and was good (green light) for the remaining 10 indicators. The completion of IOF quality standards was bad (red light) for patient identification items and FLS reference time. It was poor (amber traffic light) for initial OP screening standard and was good (green light) for the remaining 10 indicators (Figure 1).

\section{Percentage of compliance with quality of care standards.}

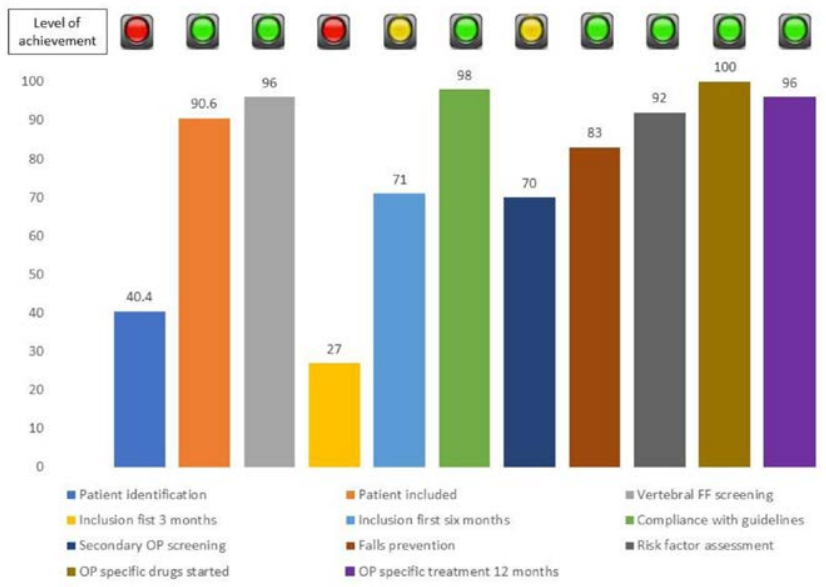

Figure 1.

Conclusion: The FLS is a multidisciplinary type A. Its operation has narrowed the gap in diagnosis, treatment, and follow-up of FF patients, especially males. It is essential to improve patient recruitment, reduce referral times and increase the overall assessment of the patients.

\section{REFERENCES:}

[1] Ganda K. et al. Models of care for the secondary prevention of osteoporotic fractures: a systematic review and meta-analysis, Osteoporos Int 2013:24:293-406.

[2] Javaid MK et al. A patient-level key performance indicator set to measure the effectiveness of fracture liaison services and guide quality improvement: a position paper of the IOF Capture the Fracture Working Group, National Osteoporosis Foundation and Fragility Fracture Network. Osteoporos Int. 2020 Jul;31(7):1193-1204.

Acknowledgements: Spanish Society of Research in Mineral and Bone Metabolism for its support through the competitive project FLS Excellence 2018 to obtain a training grant from the case management nurse.

Disclosure of Interests: Blanca Hernández-Cruz Speakers bureau: Sociedad Española de Reumatología, Abbvie, Roche, Bristol, MSD, Lilly, Pfizer, Amgen, Sanofi, Consultant of: Abbvie, Lilly, Sanofi, STADA, UCB, Amgen, Galapagos. Grant/research support from: Fundación para la Investigación Sevilla, Junta de Andalucía

Fundación Andaluza de Reumatología, Sociuedad Española de Reumatología. Francisco Jesús Olmo Montes: None declared., Maria José Miranda García: None declared., María Dolores Jimenez Moreno: None declared., María Angeles Vázquez Gómez: None declared., Mercedes Giner García: None declared. Miguel Angel Colmenero Camacho: None declared., José Javier Pérez Venegas: None declared., María José Montoya García: None declared. DOI: 10.1136/annrheumdis-2021-eular.1448 